\title{
Role of macrophages in experimental liver injury and repair in mice (Review)
}

\author{
XIAOTIAN DONG, JINGQI LIU, YANPING XU and HONGCUI CAO
}

State Key Laboratory for Diagnosis and Treatment of Infectious Diseases, The First Affiliated Hospital, College of Medicine, Zhejiang University, Hangzhou, Zhejiang 310003, P.R. China

Received July 9, 2018; Accepted December 6, 2018

DOI: $10.3892 / \mathrm{etm} .2019 .7450$

\begin{abstract}
Liver macrophages make up the largest proportion of tissue macrophages in the host and consist of two dissimilar groups: Kupffer cells (KCs) and monocyte-derived macrophages $(\mathrm{MoM} \varnothing)$. As the liver is injured, KCs sense the injury and initiate inflammatory cascades mediated by the release of inflammatory cytokines and chemokines. Subsequently, inflammatory monocytes accumulate in the liver via chemokine-chemokine receptor interactions, resulting in massive inflammatory MoM $\varnothing$ infiltration. When live $\mathrm{r}$ injury ceases, restorative macrophages, derived from recruited inflammatory monocytes (lymphocyte antigen 6 complex, locus $\mathrm{C}^{\text {hi }}$ monocytes), promote the resolution of hepatic damage and fibrosis. Consequently, a large number of studies have assessed the mechanisms by which liver macrophages exert their opposing functions at different time-points during liver injury. The present review primarily focuses on the diverse functions of macrophages in experimental liver injury, fibrosis and repair in mice and illustrates how macrophages may be targeted to treat liver disease.
\end{abstract}

\section{Contents}

1. Introduction

2. Macrophages

3. Role of macrophages in carbon tetrachloride-induced liver injury, fibrosis and repair

4. Role of macrophages in other non- $\mathrm{CCl}_{4}$ induced liver injury animal models

5. Therapeutic potential of macrophages

6. Conclusions

Correspondence to: Professor Hongcui Cao, State Key Laboratory for Diagnosis and Treatment of Infectious Diseases, The First Affiliated Hospital, College of Medicine, Zhejiang University, 79 Qingchun Road, Hangzhou, Zhejiang 310003, P.R. China E-mail: hccao@zju.edu.cn

Key words: liver injury, macrophage, inflammation, immune function, mouse

\section{Introduction}

Macrophages, originating from monocytic precursors, have multiple functions and are widely known for their phagocytic capacity, antigen-presenting function and active secretory properties. Once localized in the liver, macrophages exhibit high phagocytic activity to remove endotoxins and pernicious substances from the portal vein. Resident tissue macrophages and inflammatory monocytes recruited from bone marrow have a dual role in organ damage induced by various factors, including infection, auto-immune disorders and mechanical or toxic injuries (1). Following liver injury, the resident liver macrophages are activated and exert pro-inflammatory, pro-wound healing and restorative effects at different stages of hepatic injury and the repair response (2). Studies using animal models of chemical-induced liver injury have identified macrophages as the key regulators of liver repair and regeneration, or fibrosis. In the present review, the various functions of macrophages in hepatic toxicity are illustrated.

\section{Macrophages}

Macrophages are widely distributed phagocytic innate immune cells that have essential roles in tissue homeostasis and the host defence. The diverse tissue macrophage populations resident in most tissues of the body mainly originate from the yolk sac in the process of embryogenesis, and certain tissue macrophages are developed from fetal liver and hematopoietic progenitors at later time-points (3). For closed tissues, resident macrophages [e.g., lung alveolar macrophages and liver Kupffer cells (KCs)] mostly originate from fetal liver monocytes (4). Liver macrophages, accounting for $20-35 \%$ of hepatic non-parenchymal cells, make up the largest proportion (80-90\%) of tissue macrophages in the host and are an essential constituent of the mononuclear phagocytic system (5). They consist of two distinct populations: 'Sessile' KCs and motile liver macrophages, named as monocyte-derived macrophages (MoMø). The former, 'sessile' KCs, function as a scavenger to remove microorganisms and cell debris from the blood and clear aged erythrocytes. Furthermore, in adult tissues, they undergo self-maintenance independently of hematopoietic stem cells. Phenotypes of 'sessile' KCs are characterized as $\mathrm{F} 4 / 80^{\text {hi }}, \mathrm{CD} 11 \mathrm{~b}^{\mathrm{lo}}, \mathrm{CD} 169^{+}, \mathrm{CD} 68^{+}, \mathrm{Mac}^{-2^{+}}$and $\mathrm{CD} 80^{\mathrm{lo} /}(6-8)$. The latter, motile liver macrophages are distinct from 'sessile' 
$\mathrm{KCs}$ in terms of local migration to participate in inflammatory foci (9). The major function of motile liver macrophages is immune surveillance. Furthermore, these cells directly originate from circulating monocytes. Surface expression marker profiles of motile liver macrophages include F4/80 ${ }^{\text {int }}, \mathrm{CD}_{11} \mathrm{~b}^{\mathrm{hi}}$ and $\mathrm{CD}^{\mathrm{hi}}(8)$. These characteristics suggest that liver macrophages have distinct liver-specific gene expression patterns.

In spite of the widespread use of specific terms to define macrophage activation states [i.e., classically activated (M1) and alternatively activated (M2), no experimental standards are currently available for describing their activation (10). The original terminology using M1 and M2 macrophage activation states is derived from different macrophage gene expression patterns stimulated with interferon (IFN)- $\gamma /$ lipopolysaccharide (LPS) or interleukin (IL)-4/IL-13 (11). Within this terminology, classically activated M1 macrophages (activated by IFN- $\gamma$, LPS or high-mobility group protein 1) are functionally pro-inflammatory, microbicidal and tumoricidal. Furthermore, they exhibit anti-proliferative and cytotoxic activity. Virtually all of these features are produced by the release of numerous inflammatory cytokines, including tumor necrosis factor (TNF)- $\alpha$, IL-1, IL-6 and IL-12/23 (p40). By contrast, alternatively activated M2 macrophages downregulate the inflammatory response and facilitate tissue repair by increasing the expression of IL-10, IL-4/IL-13 and transforming growth factor (TGF)- $\beta$, as well as vascular endothelial growth factor (VEGF)- $\alpha$. Due to the complex biological characteristics of macrophage subsets, M2 macrophages are further subdivided to account for their differences: M2a, M2b and M2c activated by IL-4/IL-13, LPS/IL-1 $\beta$ and IL-10/glucocorticoids, respectively (12). However, the concept of the M1 and M2 definitions requires to be revised; this should include a reproducible experimental standard, minimal reporting standards, a definition of the activators and markers of activation $(10,13)$. In fact, macrophages display variable functions (e.g., initiation and perpetuation of inflammation, promotion of liver fibrosis and resolution of inflammation and fibrosis) in diverse microenvironments. The plasticity of macrophage activation may be elucidated by analyzing macrophage expression profiles. Furthermore, it is noteworthy that the 'restorative macrophages' in the liver fibrosis resolution phase derived from recruited lymphocyte antigen 6 complex, locus $\mathrm{C}\left(\right.$ Ly6C) ${ }^{+}$monocytes have a phenotype that is distinct from the M1/M2 definitions. Thus, the M1/M2 terminology is, at large, not applicable to liver diseases. However, whether the resolution of liver damage only requires newly recruited monocytes or hepatic macrophages capable of proliferating and switching their state of activation or that may be transformed in response to complex signals has remained to be sufficiently elucidated. In the present review, the original definition from the respective previous studies discussed is quoted when referring to mononuclear phagocyte cell types.

\section{Role of macrophages in carbon tetrachloride-induced liver injury, fibrosis and repair.}

The liver is a crucial organ of drug and toxin metabolism in the body, making it susceptible to toxic substances. When the liver is injured, monocytes and $\mathrm{KCs}$ are recruited and activated to exert numerous functional roles (1). Carbon tetrachloride $\left(\mathrm{CCl}_{4}\right)$ toxicity has various distinct ultimate outcomes, including hepatocyte necrosis, liver fibrosis and cirrhosis, or even cancer (14). Tissue repair is a complex process influenced by intricate cellular signaling pathways consisting of various cytokines, chemokines, nuclear receptors and growth factors that may trigger the expression of pro-mitogenic genes and finally promote cell division (15). Hence, the mouse model of $\mathrm{CCl}_{4}$-induced hepatic injury or fibrosis is probably the best representative experimental model for elucidating the various roles of liver macrophages in response to liver injury or fibrosis (Fig. 1).

Monocyte recruitment. Blood monocytes represent circulating precursors of tissue dendritic cells and macrophages, and may be divided into two major subsets in mice: $\mathrm{Ly} 6 \mathrm{C}^{+/ \mathrm{hi}}$ and Ly6C ${ }^{-/ l o w}$ monocytes. Ly6C ${ }^{+}$mouse monocytes highly express the chemokine receptors $\mathrm{C}-\mathrm{C}$ motif chemokine receptor 1 (CCR1) and CCR2, whereas murine Ly6C- monocytes mainly express CCR5 and $\mathrm{C}-\mathrm{X} 3-\mathrm{C}$ motif chemokine receptor 1 (CX3CR1) (16). The early recruitment of $\mathrm{Ly}^{6} \mathrm{C}^{+}$monocytes, but not of Ly6 $\mathrm{C}^{-}$monocytes, to the liver upon toxic injury is mediated by CCR2 [ligand: C-C motif chemokine ligand 2 (CCL2)] and CCR8 (ligand: CCL1). Studies using CCR2-deficient (CCR2 $2^{-/}$) and monocyte chemoattractant protein $(\mathrm{MCP})-1^{-/}$mice or specific blockade suggested that CCR 2 mediates the early accumulation of inflammatory $\mathrm{Ly} \mathrm{C}^{+}$monocytes in the damaged murine liver (17). CCR8 is also crucial for $\mathrm{Ly} 6 \mathrm{C}^{+}$monocyte infiltration into the injured murine liver (18). Furthermore, Ly $6 \mathrm{C}^{+}$monocytes, migrating from the blood to tissues affected by infection, may differentiate into inflammatory macrophages in inflamed tissues (19). Of note, Ly6 $\mathrm{C}^{-}$monocytes have a more patrolling role at the endothelium in a lymphocyte function-associated antigen-1and CX3CR1-dependent fashion, acting as scavengers and orchestrating tissue repair (20), without inflammatory stimuli. It was recently noted that $\mathrm{Ly} 6 \mathrm{C}^{-}$monocytes do not represent a distinct lineage, but instead originate from $\mathrm{Ly} 6 \mathrm{C}^{+}$monocytes regulated by CCAAT/enhancer binding protein $\beta$ in the bone marrow and blood, and that the lifespan of Ly $6 \mathrm{C}^{-}$monocytes may be negatively controlled by $\mathrm{Ly} 6 \mathrm{C}^{+}$peripheral blood monocytes (21). A systematic assessment of the differential roles of these monocyte subsets and their recruitment dynamics in liver injury is required prior to the development of therapeutic strategies aimed at targeting these monocyte subsets.

Regulation of macrophage activation. The failure of $\mathrm{CCl}_{4}$-induced liver fibrosis matrix degradation resulting from the depletion of scar-associated macrophages (SAMs) in the process of recovery and the reduction of scarring and myofibroblast activation resulting from SAM depletion during the injury stage suggest that macrophages exert distinct functions in the same tissue. Duffield et al (22) identified two distinct populations of SAMs: One derived from circulating monocytes and the other likely derived from KCs. They subsequently identified the $\mathrm{CD} 11 \mathrm{~b}^{\text {hi }} \mathrm{F} 4 / 80^{\text {int }} \mathrm{Ly} \mathrm{C}^{\mathrm{lo}}$ macrophage subset as the 'restorative macrophage group', which originated from recruited inflammatory monocytes (Ly6 $\mathrm{C}^{\text {hi }}$ monocytes), and as the governing matrix metallopeptidase (MMP)-expressing subset during most active fibrosis resolution. Furthermore, a study on the depletion 


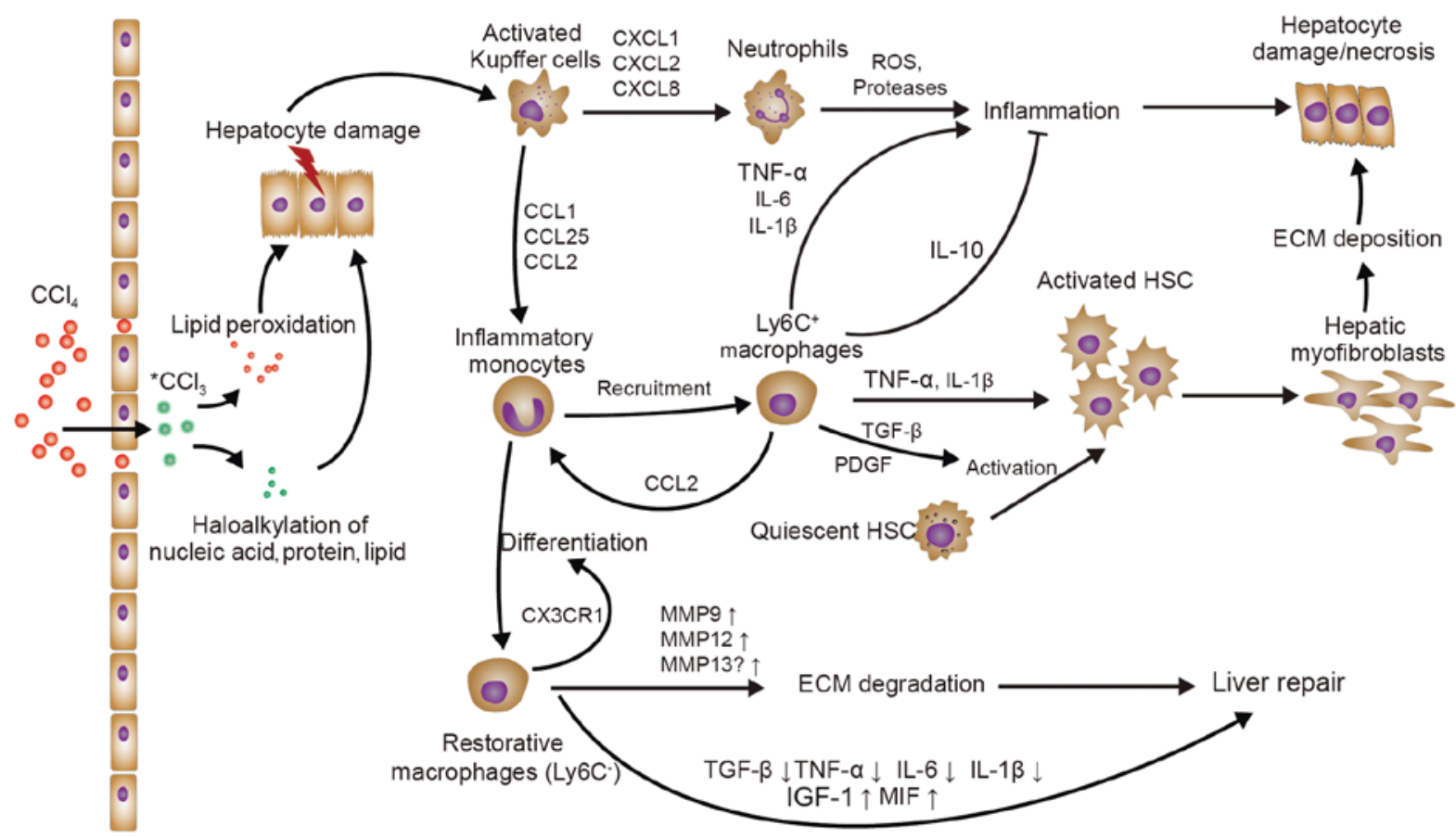

Figure 1. The role of macrophages in $\mathrm{CCl}_{4}$-induced liver injury/fibrosis. $\mathrm{KCs}$ sense the initial liver injury and mainly recruit monocytes (Ly6C $\mathrm{C}^{+}$) and neutrophils, further aggravating the liver inflammation. Ly6C ${ }^{+}$macrophages directly activate HSCs via TGF- $\beta$ and promote the survival of activated HSCs through TNF- $\alpha$ and IL-1 $\beta$ in liver fibrosis. On the other hand, recruited Ly6C $\mathrm{C}^{+}$monocytes may differentiate into Ly6C'- 'restorative' macrophages, which promote the resolution of liver injury. KC, Kupffer cell; HSCs, hepatic stellate cells; TNF, tumor necrosis factor; IL, interleukin; TGF, transforming growth factor; Ly6c, lymphocyte antigen 6 complex, locus C; IGF, insulin-like growth factor; MMP, matrix metallopeptidase; ECM, extracellular matrix; ROS, reactive oxygen species; PDGF, platelet-derived growth factor; CXCL1, C-X-C motif chemokine ligand 1; CCL1, C-C motif chemokine ligand 1; CX3CR1, C-X3-C motif chemokine receptor 1 ; MIF, macrophage migration inhibitory factor.

of this subset via diphtheria toxin administration in CD11b promoter-diphtheria toxin receptor transgenic mice revealed failure of fibrosis resolution (23). In addition, exogenous M1-polarized macrophages were the most efficacious for liver fibrosis therapy compared with M0 and M2 macrophages, which is possibly the result of recruitment and 'polarization' of endogenous macrophages into restorative Ly6C $\mathrm{C}^{\text {lo }}$ macrophages (24). However, Karlmark et al (17) indicated that the Ly6 $\mathrm{C}^{\text {hi }}$ macrophage population, derived from inflammatory Ly6 $\mathrm{C}^{\text {hi }}$ monocytes, has a promoting role in fibrogenesis. Microarray analysis of these liver macrophage populations implied differential gene expression profiles, including chemokines, cytokines, growth factors, matrix-degrading enzymes, as well as opsonins, e.g., phagocytosis-associated, peroxisome proliferator-activated receptor- $\gamma$-targeted and macrophage phenotype markers (23). Assessment of the origin of the 'restorative macrophage population' revealed that Ly6 $\mathrm{C}^{\text {hi }}$ monocytes switch to the anti-fibrotic Ly6C ${ }^{\text {lo }}$ macrophage phenotype, rather than representing a distinct subset (25). Furthermore, Tacke and Zimmermann (26) indicated that another macrophage population, KCs, possess a crucial role in sensing hepatic injury and initiating inflammatory responses, whereas Ly6 $\mathrm{C}^{\mathrm{hi}}$ macrophages are relevant to chronic inflammation and fibrogenesis.

Mediators derived from macrophages initiate hepatic inflammation and fibrosis. KCs are phagocytic innate immune cells that clear dead cells and cell debris, and maintain liver homeostasis; furthermore, they are able to sense liver injury and subsequently orchestrate pro-inflammatory processes. Similar to toll-like receptors (TLRs), one of the critical roles of KCs is the ability to sense liver damage via pathogen-associated molecular patterns (PAMPs) or damage-associated molecular patterns (DAMPs).

In the liver, PAMPs (e.g., those associated with LPS, fungal components and flagellin) mostly originate from the gut as a result of gut bacterial translocation. However, DAMPs (e.g., adenosine triphosphate and DNA fragments) mainly originate from damaged hepatocytes (27). One such process that leads to DAMPs is $\mathrm{CCl}_{4}$-induced hepatic toxicity.

$\mathrm{CCl}_{4}$-associated hepatic toxicity features initial hepatocellular structural derangements, followed by cellular metabolic changes that result in further damage and may cause pathological changes (e.g., necrosis, apoptosis or fibrosis) (28). Furthermore, the pathologic effects of $\mathrm{CCl}_{4}$ lead to the release of DAMPs and activate KCs to initiate inflammatory cascades. Activated KCs secrete a great number of chemokines and cytokines, resulting in further recruitment of chemokines and leukocytes (e.g., monocytes and neutrophils) to areas of inflammation. Specifically, activated $\mathrm{KC}$ s produce $\mathrm{CXC}$-chemokine ligand 1 (CXCL1), CXCL2 and CXCL8 (IL-8).

CXCL1, CXCL2 and CXCL8 are central chemokines that attract neutrophils mainly through the chemokine receptors CXCR1 and CXCR2. Neutrophil recruitment increases the release of reactive oxygen species (ROS) and proteases, leading to hepatocyte necrosis (29). In parallel, KCs secrete CCL2 to increase circulating $\mathrm{CCR} 2{ }^{+} \mathrm{Ly} 6 \mathrm{C}^{+}$monocytes that massively expand the local macrophage pool (17). CCR2 $2^{+} \mathrm{Ly}_{6 \mathrm{C}^{+}}$monocyte migration into the liver after injury is functionally critical for the maintenance of liver inflammation and fibrogenesis. 
The functionality of MoMø not only depends on CCL2, but also on CCL1 and CCL25, which induce the migration of pro-inflammatory monocytes/macrophages via CCR8 and CCR9, respectively $(18,30,31)$. Ultimately, KCs sense initial liver injury and are responsible for monocyte and neutrophil recruitment, further aggravating liver inflammation.

With inflammatory stimuli, the program of cytokine production by KCs, triggered by TLR signaling, is more complex than the simple result from the activation of transcription factors. KCs are poised to swiftly respond to PAMPs or DAMPs with the production of TNF. In KCs, the production of TNF usually precedes and generally promotes the carefully orchestrated release of many other inflammatory mediators including IL-6, IL-12/23 (p40) and type I interferons (e.g., IFN- $\gamma$ and TNF- $\alpha$ ) (32). IFN- $\gamma$ is a hallmark cytokine of Th1 cells that greatly increases the production of inflammatory mediators by macrophages. Consequently, KCs activated by IFN- $\gamma$ express numerous pro-inflammatory cytokines (e.g., IL-6 and TNF- $\alpha$ ) with the enhancement of nuclear factor (NF)- $\mathrm{kB}$ gene expression. While these pro-inflammatory signals may lead to enhanced liver inflammation and injury, they also have protective effects on the liver. IL-6 signaling, via signal transducer and activator of transcription (STAT) 3 activation, markedly increases after acute $\mathrm{CCl}_{4}$-induced hepatic damage and promotes liver proliferation by upregulating the expression of growth factors (e.g., hepatocyte growth factor), increases hepatocyte responsiveness and also inhibits hepatocyte apoptosis. TNF- $\alpha$ has a major role in the regulation of IL- 6 secretion and liver regeneration via induction of NF-kb $(33,34)$.

Severe liver damage caused by high doses of $\mathrm{CCl}_{4}$ may cause death or liver self-healing. However, repeated injections of low doses of $\mathrm{CCl}_{4}$ in rodents lead to liver fibrosis or liver cirrhosis. In fibrogenesis, Pradere et al (35) revealed that liver macrophages promote myofibroblast survival in an NF- $\kappa B$-dependent manner, and macrophage-derived TNF- $\alpha$ and IL-1 $\beta$ enhance the survival of activated hepatic stellate cells (HSCs). Activated HSCs and hepatic myofibroblasts exert pro-fibrogenic activity, as they may increase the levels of fibrotic matrix proteins, thus inhibiting fibrotic degradation (36). Furthermore, Karlmark et al (17) demonstrated that $\mathrm{CCR} 2$ has a crucial role in the migration of $\mathrm{Ly} 6 \mathrm{C}^{\mathrm{hi}}$ monocytes, which directly activates HSCs via TGF- $\beta$, upon chronic liver injury.

Aside from TGF- $\beta$, platelet-derived growth factor (PDGF) expressed in liver macrophages also contributes to liver fibrogenesis (37). PDGF promotes HSC proliferation and activation through PDGF receptor and does not have this effect after neutralization (38). However, the fibrosis-associated TLR signaling of KCs and HSCs remains elusive. Perugorria et al (39) reported that once TLR is activated, elevated Tpl 2 may be identified as an essential signal transducer in KCs and HSCs, and promotes fibrogenic gene expression.

Mediators derived from macrophages suppress liver inflammation and decelerate fibrogenesis. KCs have an important role in the initiation and perpetuation of liver inflammation, which are necessary for the host defence, but if not controlled, they may cause hepatic damage, fibrosis and cirrhosis. Four cytokines with the ability to downregulate macrophage function have been identified: IL-4, IL-10, IL-13 and TGF- $\beta 1$, of which IL-10 appears to have a broader and deeper effect. Importantly, IL-10 is released from macrophages, type 2 T-helper (Th2) cells and stromal cells. IL-10 inhibits the expression of NF- $\mathrm{KB}$, the production of pro-inflammatory cytokines by Th1 cells, macrophages and neutrophils, the proliferation of hepatocytes and fibrogenesis during liver repair $(40,41)$. Hepatic macrophages not only promote hepatic fibrosis by activating HSCs in chronic hepatic damage, but also contribute to the resolution of fibrosis by degrading the extracellular matrix (ECM) (26). Macrophages produce gelatinases (MMP9, MMP12 and MMP13) under different circumstances, resulting in complex ECM degradation. During fibrosis regression, recruited Ly6C- monocytes differentiate into Ly6C+ 'restorative' macrophages, with upregulation of MMPs (MMP9 and MMP12), downregulation of pro-inflammatory cytokines and chemokines, enhanced expression of insulin-like growth factor 1 (IGF-1) and genes associated with anti-inflammatory or antifibrotic effects, including CX3CR1, CD74 and macrophage migration inhibitory factor, and a reduction in TGF- $\beta$, thus promoting recovery from injury. Furthermore, SAMs produce MMP13, which may disassemble the interstitial matrix and promote fibrosis resolution $(23,42)$. However, whether KCs or Ly6C 'restorative' macrophages are the source of MMP13 remains elusive. In addition, KCs are a major source of CXCL9, which ameliorate liver fibrogenesis (43). Furthermore, CX3CR1 is a major regulator of monocyte differentiation and survival in the liver and protects against liver fibrosis (44).

\section{Role of macrophages in other non- $\mathrm{CCl}_{4}$ induced liver injury animal models}

Macrophages in cholestatic liver injury, fibrosis and repair. Bile duct ligation (BDL) is a commonly used animal model of cholestatic liver disease. Ligation of the common bile duct performed at a standardized site prevents bile flow and causes bile reflux followed by cholangitis, coagulation defects and hepatic damage, and may even result in biliary fibrosis and cirrhosis (45). The absence of bile salts and bile in the intestines after BDL may promote translocation of endotoxins and growth of endotoxin-producing bacteria, resulting in cholangitis (45). KCs are a major type of defence cell for the liver, as they remove endotoxins (e.g., LPS) and phagocytose bacteria under normal conditions. However, the intracellular bactericidal function of KCs in the BDL model is impaired as a result of high levels of hydrophobic bile acids in the serum. The altered sensitivity of KCs to endotoxins in BDL induces overproduction of TNF- $\alpha$ and IL-6, which leads to liver injury, but KC blockade may suppress systemic cytokine production and improve survival under these conditions (46). Furthermore, toxic bile salts directly cause rodent hepatocyte apoptosis through activation of Fas (47), which leads to apoptotic body formation and results in HSC activation through phagocytosis of apoptotic bodies and enhancement of fibrogenesis (48). The engulfment of hepatocyte apoptotic bodies by KCs has also been reported to promote liver inflammation and fibrogenesis, which is mediated by death ligands and cytokines, including TNF- $\alpha$, TNF-related apoptosis-inducing ligand (TRAIL), Fas and TGF- $\beta$ (49). However, later studies demonstrated that KCs abrogate cholestatic liver injury via IL-6 and 
acid sphingomyelinase-dependent mechanisms $(50,51)$. In conclusion, KCs may have protective and promoting roles in cholestatic liver injury.

Similar to that in cholestatic liver injury, KCs also possess a dual role in BDL-induced liver fibrosis. Although KCs generate death ligands to promote liver inflammation (49) and produce acid sphingomyelinase to activate AKT in hepatocytes, which is required for regeneration (51), higher expression of TGF- $\beta$, a fibrogenic cytokine, has also been observed (49,51). Liver injury is associated with increased hepatic exposure to LPS. In contrast to KCs, LPS mainly targets TLR4 in HSCs, and makes HSCs sensitive to TGF- $\beta$ via the MyD88/NF- $\kappa$ B-dependent pathway (52). Furthermore, high levels of IL-17A have been detected in fibrotic livers (53). IL-17A is generated predominantly by effector $\mathrm{CD}^{+} \mathrm{T}$ (Th17) cells, which differentiate from Th0 cells, and is regulated by IL-6, TNF, TGF- $\beta$ and IL-23 (54). IL-17 stimulates KCs to further upregulate IL-17A levels, increasing IL-17 receptor A expression and induces the production of the pro-inflammatory cytokines TNF- $\alpha$, IL-6 and IL- $1 \beta$, as well as the fibrogenic cytokines TGF- $\beta 1$ and PDGF (53). IL- 6 and TGF- $\beta 1$ further facilitate the differentiation and expansion of Th17 cells (53). In addition, PDGF promotes HSC proliferation and activation (55). However, IL-17 production may be inhibited by activation of cannabinoid receptor 2 in macrophages (56). Furthermore, $\mathrm{CD}^{+} 8^{+} \mathrm{KCs}$ may clear apoptotic cholangiocytes via phagocytosis, resulting in the upregulation of MMP3, MMP8 and MMP9, which contribute to the reversal of biliary fibrosis (57).

Role of macrophages in thioacetamide-induced liver injury, fibrosis and repair. Thioacetamide (TAA), a centrilobular hepatotoxin, is widely applied to induce acute or chronic hepatic disease (58). Initial lesions in the liver begin with a cytochrome P450 family 2 subfamily E member 1-mediated two-step bioactivation of TAA into thioacetamide sulfoxide and further to thioacetamide-S,S-dioxide (58), which is mainly distributed in zone 3 (centrilobular area), resulting in cytotoxicity. Injured or necrotic hepatocytes release S100 proteins, high-mobility group box proteins (HMGBs) and heat shock proteins (HSPs) as DAMPs (59). HMGBs and S100 proteins may be recognized by TLR-2 and TLR-4 (60) to produce pro-inflammatory cytokines IL-6, TNF $\alpha$ and IL-1 $\beta$. However, HSP25 may act to protect liver cells by macrophages invading the hepatic lesion (61). Gadolinium chloride (GD) is used to selectively inactivate $\mathrm{KCs}$, resulting in decreased serum levels of TNF- $\alpha$ and IL-6, reduced TAA-induced liver injury, as well as enhanced metallothionein and HSP70 expression (62). Furthermore, GD treatment decreases the numbers of $\mathrm{CD}^{+} 8^{+}$and $\mathrm{CD} 163^{+}$macrophages and inhibits TGF- $\beta 1$ expression in macrophages (63). $\mathrm{CD}^{+} 8^{+}$cells with maintained high levels of MCP-1 expression have been detected in injured perivascular areas for up to 20 days, whereas $\mathrm{CD} 63^{+}$cells gradually decreased in number in the mid-zonal areas after day 3 (64). In addition, depletion of M1 (expressing CD68 and major histocompatibility complex class II) and M2 (expressing CD163 and CD204) macrophages by liposomal clodronate, may aggravate and prolong coagulation necrosis of hepatocytes. This has been reported to be primarily due to the depletion of M2 macrophages, revealing a remodeling stage dominated by M2 (65). However, KCs may release nitric oxide and trigger post-necrotic hepatocyte regeneration following TAA treatment (66). Therefore, KCs may also possess a dual role in TAA-induced hepatic injury.

Repeated injection of TAA or the addition of TAA to drinking water has been widely used to induce hepatic fibrosis. Similarly, HSCs also have a critical role in TAA-induced fibrosis (67). PDGF-B may be the major cytokine for HSC activation in TAA-induced liver fibrosis (68). Furthermore, galectin-3 (Gal-3) ${ }^{+}$macrophages are also involved in the initiation of fibrosis via the activation of HSCs (69). However, Gal- $3^{+}$macrophages possess M1 and M2 properties in the advanced stage of liver fibrosis (70). To remodel tissue in the fibrotic liver, a splenectomy may be effective due causing an accumulation of $\mathrm{Ly} 6 \mathrm{C}^{\mathrm{lo}}$ macrophages and the disappearance of hepatic progenitor-like cells (71).

Role of macrophages in acetaminophen-induced acute liver injury and repair. Acetaminophen (APAP) overdose-induced liver injury is the most common cause of drug-induced hepatotoxicity in Western countries. An APAP overdose may result in mitochondrial dysfunction, ATP depletion and DNA fragmentation, which eventually cause cell necrosis (72). In addition to initial hepatocyte necrosis, the release of DAMPs, including DNA fragments, HMGB-1 and HSPs, induces $\mathrm{KC}$ activation and an inflammatory response, which also contributes to the disease (73). Although HMGB-1 has several separate receptors, including TLR2, TLR4 and TLR9, TLR4 is a pivotal receptor for macrophage activation and cytokine production (TNF, CXCL2, IL-6, IL-1 $\beta$ and IL-10) (74). HMGB-1/TLR4-dependent activation of IL-23 release from macrophages promotes $\gamma \delta \mathrm{T}$ cells to produce IL-17A, which recruits neutrophils participating in sterile inflammation (75). Furthermore, neutrophil infiltration to necrotic areas also depends on the CXCR2/formyl peptide receptor 1 axis (76). However, the role of neutrophils in liver damage is controversial, as neutrophils may either aggravate or have no effect on liver injury $(77,78)$.

A total of three distinct macrophage subsets were identified during APAP-induced acute liver injury and repair (Fig. 2): Resident KCs, Ly6C ${ }^{\text {hi }}$ monocytes/macrophages and Ly6C ${ }^{\text {lo }}$ MoM $\varnothing$. Although KCs produce TNF- $\alpha$ and IL-1 $\beta$, there is no credible evidence that KCs directly cause liver cell damage (79). Furthermore, the recently discovered Mer tyrosine kinase-expressing macrophage phenotype that has hepatoprotective effects, including neutrophil apoptosis and clearance, is mainly derived from the $\mathrm{KC}$ population (80). It is worth noting that the number of KCs is decreased upon APAP application, and then increased by self-renewal. In addition, Ly6C ${ }^{\text {hi }}$ monocytes may be recruited into the liver and trans-differentiated into the Ly6 $\mathrm{C}^{\text {lo }} \mathrm{MoM} \varnothing$ phenotype through CX3CL1/CX3CR1, MCP-1/CCR2 and in a monocyte colony-stimulating factor-dependent manner. In addition, Ly $6 \mathrm{C}^{\text {hi }}$ monocytes and $\mathrm{Ly} 6 \mathrm{C}^{\mathrm{lo}} \mathrm{MoM} \varnothing$ contribute to liver recovery. However, Zigmond et al (81) and Mossanen et al (82) demonstrated that CCR2Ly6C ${ }^{\text {hi }}$ monocytes/macrophages promote APAP hepatotoxicity at an early stage. Another study has indicated that $\mathrm{Ly} 6 \mathrm{C}^{\text {hi }}$ monocytes and Ly6 $\mathrm{C}^{\text {lo }} \mathrm{MoM} \varnothing$ are likely to work together: The former promote apoptosis of ROS-producing neutrophils and the latter promote neutrophil clearance (83). In addition, Ly6C $\mathrm{C}^{\text {hi }}$ monocytes have higher levels of VEGF-A, 


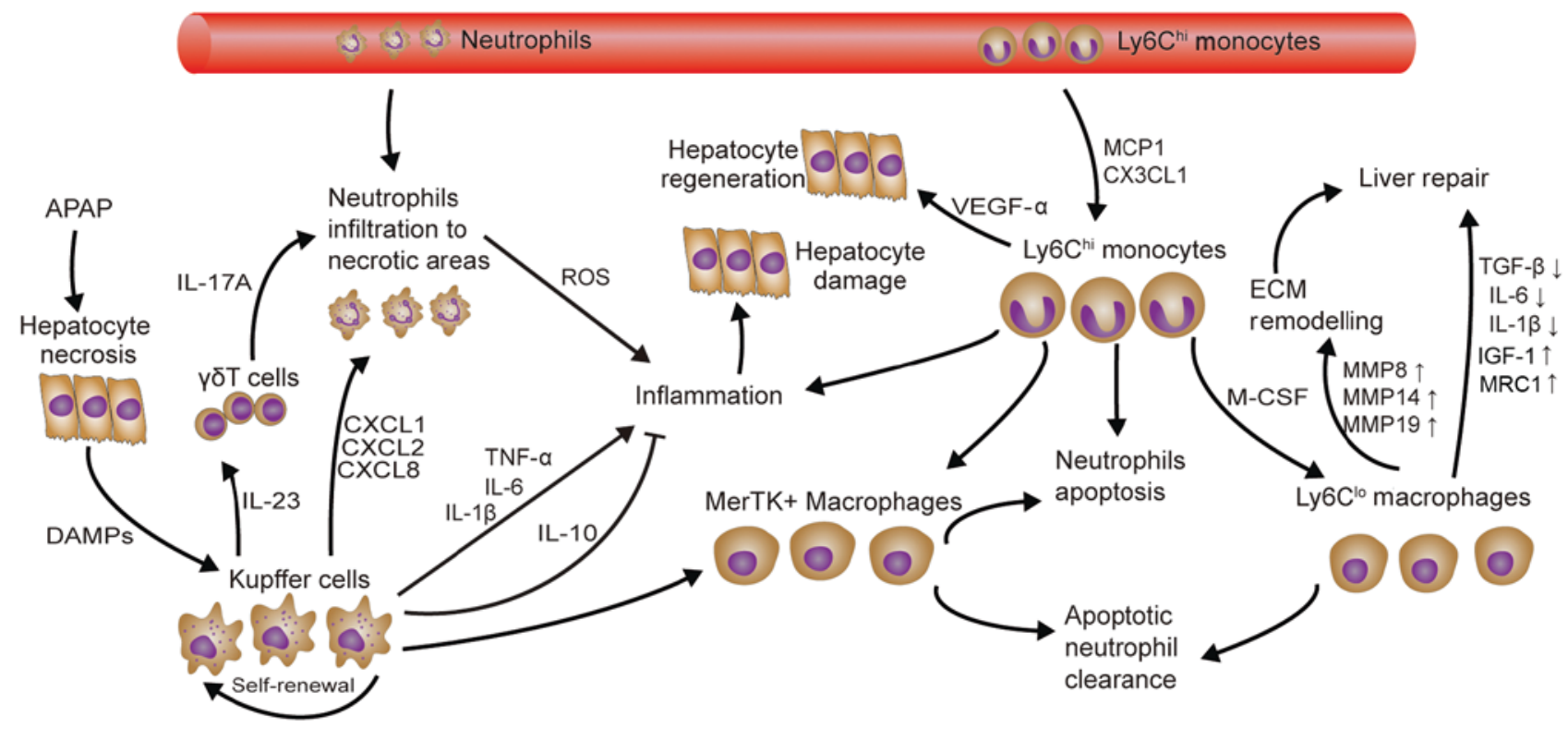

Figure 2. Role of macrophages in APAP-induced acute liver injury. APAP-induced liver injury is aggravated by the activation of KCs as a result of DAMP release from necrotic hepatocytes, causing neutrophil infiltration and subsequent Ly6 $\mathrm{C}^{\mathrm{hi}}$ monocyte recruitment. Ly6 $\mathrm{C}^{\text {hi }}$ monocytes and their Ly6 $\mathrm{C}^{+}$macrophage descendants then promote neutrophil apoptosis and clearance, hepatocyte regeneration and remodeling of the ECM. MerTK ${ }^{+}$macrophages derived from KCs and monocyte-derived macrophages may also promote neutrophil apoptosis and clearance. KC, Kupffer cell; TNF, tumor necrosis factor; IL, interleukin; TGF, transforming growth factor; Ly6c, lymphocyte antigen 6 complex, locus C; IGF, insulin-like growth factor; MMP, matrix metallopeptidase; ECM, extracellular matrix; CXCL1, C-X-C motif chemokine ligand 1; CX3CR1, C-X3-C motif chemokine ligand 1; DAMP, damage-associated molecular pattern; APAP, acetaminophen; M-CSF, monocyte colony-stimulating factor; MCP1, monocyte chemoattractant protein 1; VEGF, vascular endothelial growth factor; MerTK, Mer tyrosine kinase; MRC1, mannose receptor C-type 1.

TGF- $\beta 1$, IL-6, IL-1 $\beta$ and MMP18 gene expression, whereas Ly6 $\mathrm{C}^{\text {lo }} \mathrm{MoM} \varnothing$ express higher levels of pro-restorative genes, including IGF-1 and mannose receptor 1 . In comparison with $\mathrm{KCs}$, Ly6 ${ }^{\text {hi }}$ monocytes and Ly6 $\mathrm{C}^{\text {lo }} \mathrm{MoM} \varnothing$ also express high levels of MMP8, MMP14 and MMP19, which are important for ECM re-modeling (81).

Role of macrophages in D-galactosamine-induced acute liver failure. D-galactosamine (D-GalN) may inhibit the synthesis of mRNA and proteins that cause hepatocyte necrosis. Furthermore, D-GalN-induced necrosis was reported to increase gut permeability and cause endotoxemia in a rat model but not in a mouse model (84). This is also thought to contribute to hepatotoxicity. Thus, D-GalN/LPS co-administration is commonly used to induce liver injury in mice (85). In fact, $\mathrm{D}-\mathrm{GalN}$ increases the sensitivity of rabbits, rats and mice to LPS, possibly by upregulating TLR4 expression in liver macrophages and producing lethal toxicity $(86,87)$. Along these lines, depletion of TLR4 leads to a decreased inflammatory response and hepatic injury (88). Under LPS stimulation, KCs secrete TNF- $\alpha$, and cause hepatocyte apoptosis and the release of other cytokines (IL-1 and IL-6) (85). However, TNF- $\alpha$ appears to be the major pro-inflammatory mediator, as macrophage autophagy may inhibit the production of IL-1 $\beta$. In addition, IL-6 treatment was reported to have a beneficial effect and reduce the expression of TNF- $\alpha$ and MCP-1, and promote macrophage polarization towards M2 in D-GalN/LPS induced liver injury models $(89,90)$. Besides LPS, cytosine-phosphate-guanine DNA and polyinosinic:polycytidylic acid also exert hepatic toxicity mediated by TNF- $\alpha$ in D-GalN-sensitized mice (91). The depletion of macrophages and the inhibition of TNF- $\alpha$ production protected against D-GalN/LPS-induced hepatic injury $(92,93)$.
Furthermore, increasing the production of IL-10 in macrophages via treatment with IL-35 also provided a therapeutic effect (94).

Role of macrophages in liver ischemia/reperfusion injury and repair. Ischemia/reperfusion injury (IRI) may be divided into two types, namely those with 'warm' ischemia and 'cold' ischemia. Warm ischemia may occur during liver surgery, shock or trauma, whereas cold ischemia may develop in liver transplants. However, the two types share a common mechanism in inflammatory immune regulation (95). HMGB1 may be released from hepatocytes in response to hypoxia/ischemia and remain at high levels for up to $24 \mathrm{~h}$ after reperfusion, resulting in liver inflammation and injury mediated by TLR4 (96). Inhibition of TLR4 and KCs simultaneously was reported to reduce TNF- $\alpha$, IL-6, CXCL2 production and IRI $(97,98)$. Conversely, KCs also exert protective effects in IRI through IL-10 and heme oxygenase-1 (HO-1) (99,100). Furthermore, HO-1 modified MoMø may prevent IRI, possibly via the HO-1/STAT3 axis $(101,102)$. In addition, neutrophils recruited by CXCL2 and CD4 ${ }^{+} \mathrm{T}$ cells, which regulate macrophage and neutrophil function via IFN- $\gamma$ and IL-10, also have an important role in IRI (103).

Role of macrophages in non-alcoholic fatty liver disease. Non-alcoholic fatty liver disease (NAFLD), which encompasses simple fatty liver (SFL), non-alcoholic steatohepatitis (NASH) and associated cirrhosis, are usually linked to obesity, insulin resistance and hyperlipidemia (104). The phenotypic switch of adipose tissue macrophages (ATMs) from M2 ATMs to M1 ATMs contributes to insulin resistance (IR) and hepatic steatosis in obese mice (105). IR, as well as concomitant hyperglycemia and hyperinsulinemia, may lead to increased production of free fatty acids (FFAs), but reduced FFA 


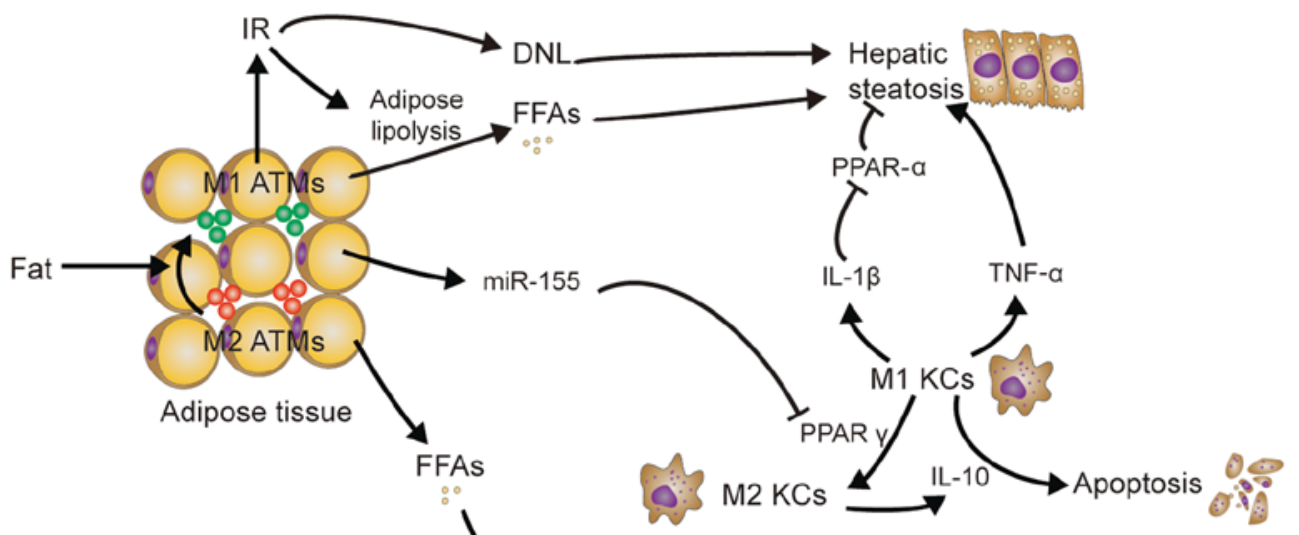

Stage 1: SFL

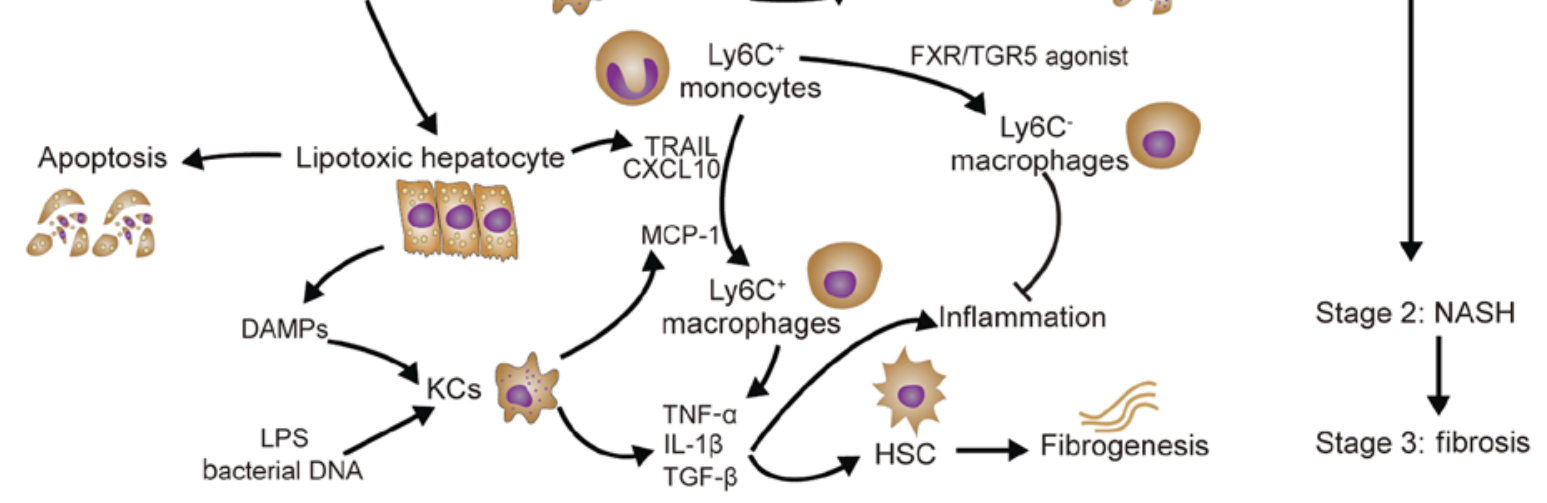

Figure 3. Role of macrophages in non-alcoholic fatty liver disease. Obesity-associated IR and KCs contribute to hepatic steatosis. LPS and bacterial DNA derived from the intestine, as well as DAMPs released from FFA-induced lipotoxic hepatocytes, activate $\mathrm{KCs}$, resulting in Ly $6 \mathrm{C}^{+}$macrophage chemotaxis and the release of pro-inflammatory cytokines (TNF- $\alpha$ and IL-1 $\beta$ ), which promote liver inflammation. In addition to promoting liver inflammation, TNF- $\alpha$ and IL-1 $\beta$ may activate HSCs to upregulate the production of TIMP1, an inhibitor of MMPs that causes fibrogenesis. KC, Kupffer cell, ATMs, adipose tissue macrophages; DNL, de novo lipogenesis; PPAR, peroxisome proliferator activated receptor; TNF, tumor necrosis factor; IL, interleukin; MMP, matrix metallopeptidase; FFA, free fatty acids; TIMP1, tissue inhibitor of metallopeptidases-1; TRAIL, TNF-related apoptosis-inducing ligand; SFL, simple fatty liver; NASH, non-alcoholic steatohepatitis; DAMP, damage-associated molecular pattern; LPS, lipopolysaccharide; miR, microRNA; IR, insulin resistance; HSCs, hepatic stellate cells; TGF, transforming growth factor; PPAR peroxisome proliferator-activated receptor; FXR, farnesoid X receptor; TGF5, Takeda G-protein receptor 5; TRAIL, TNF-related apoptosis-inducing ligand; CXCL, C-X-C motif chemokine ligand; Ly6c, lymphocyte antigen 6 complex, locus C.

oxidation and increased de novo lipogenesis, which results in lipid accumulation in hepatocytes and hepatic steatosis (106). In addition, KCs promote hepatic steatosis (Fig. 3). MicroRNA-155 produced by ATMs under obesity conditions may target hepatocytes and reduce the expression of peroxisome proliferator activated receptor (PPAR) $\gamma$, which is required for $\mathrm{KC}$ polarization to the M2 phenotype $(107,108)$; this results in an M1-predominant phenotype of KCs. M1 KCs produce IL-1 $\beta$, which inhibits PPAR $\alpha$ expression and leads to a suppression of fat oxidation and an aggravation of hepatic steatosis (109). Depletion of KCs and inhibition of TNF- $\alpha$ reduces hepatic steatosis in rats fed a high-fat/sucrose diet (110). Conversely, M2 KCs produce IL-10 to promote M1 $\mathrm{KC}$ apoptosis and protect against NAFLD (111).

The mechanisms of NASH have been described by two different hypotheses: The 'two-hit' hypothesis (112) and the 'multiple parallel hits' hypothesis (113). However, the identification of KCs as promoters of hepatic steatosis (as mentioned above) challenges the latter hypothesis. Indeed, palmitic acid and stearic acid (saturated fatty acids), and oleic acid (a monounsaturated fatty acid) may all prompt hepatocyte apoptosis (lipotoxicity) (114). Furthermore, lipotoxic hepatocytes may release TRAIL and CXCL10 to induce macrophage chemotaxis $(115,116)$. Furthermore, FFAs may also promote hepatocytes to release HMGB1 (117). However, Ly6C ${ }^{+}$ macrophage infiltration may be mainly dependent on MCP-1 produced by $\mathrm{KCs}$, as only early depletion of $\mathrm{KCs}$ prevents the development of NASH (118). In addition, inhibition of MCP-1 may also inhibit the development of steatohepatitis (119). Ultimately, macrophage accumulation aggravates liver inflammation via the release of TNF- $\alpha$ and IL-1 $\beta$ (120). However, bile acid receptor farnesoid $\mathrm{X}$ receptor/Takeda G-protein receptor 5 agonist was reported to contribute to the intrahepatic monocyte phenotype Ly6C $\mathrm{C}^{\text {low }}$ (121). Endotoxin and bacterial DNA derived from the intestine may also activate the release of TLR4 and TLR9 from KCs separately, resulting in IL-1 $\beta$ expression. In addition to promoting liver inflammation, TNF- $\alpha$ and IL- $1 \beta$ activate HSCs to upregulate the production of tissue inhibitor of metallopeptidases-1, which inhibits MMPs and causes fibrogenesis $(122,123)$. Leptin produced by activated HSCs may also further promote liver fibrosis, which is possibly mediated by TGF- $\beta 1$ expression (124).

\section{Therapeutic potential of macrophages}

Understanding the different roles and mechanisms of macrophages in hepatic damage, fibrosis and repair is critical for the development of novel therapies for hepatic diseases. When the liver is injured, $\mathrm{KCs}$ sense initial liver injury and initiate inflammatory cascades. Subsequently, inflammatory monocytes accumulate in the liver via chemokine-chemokine receptor interactions. When liver injury ceases, restorative macrophages 


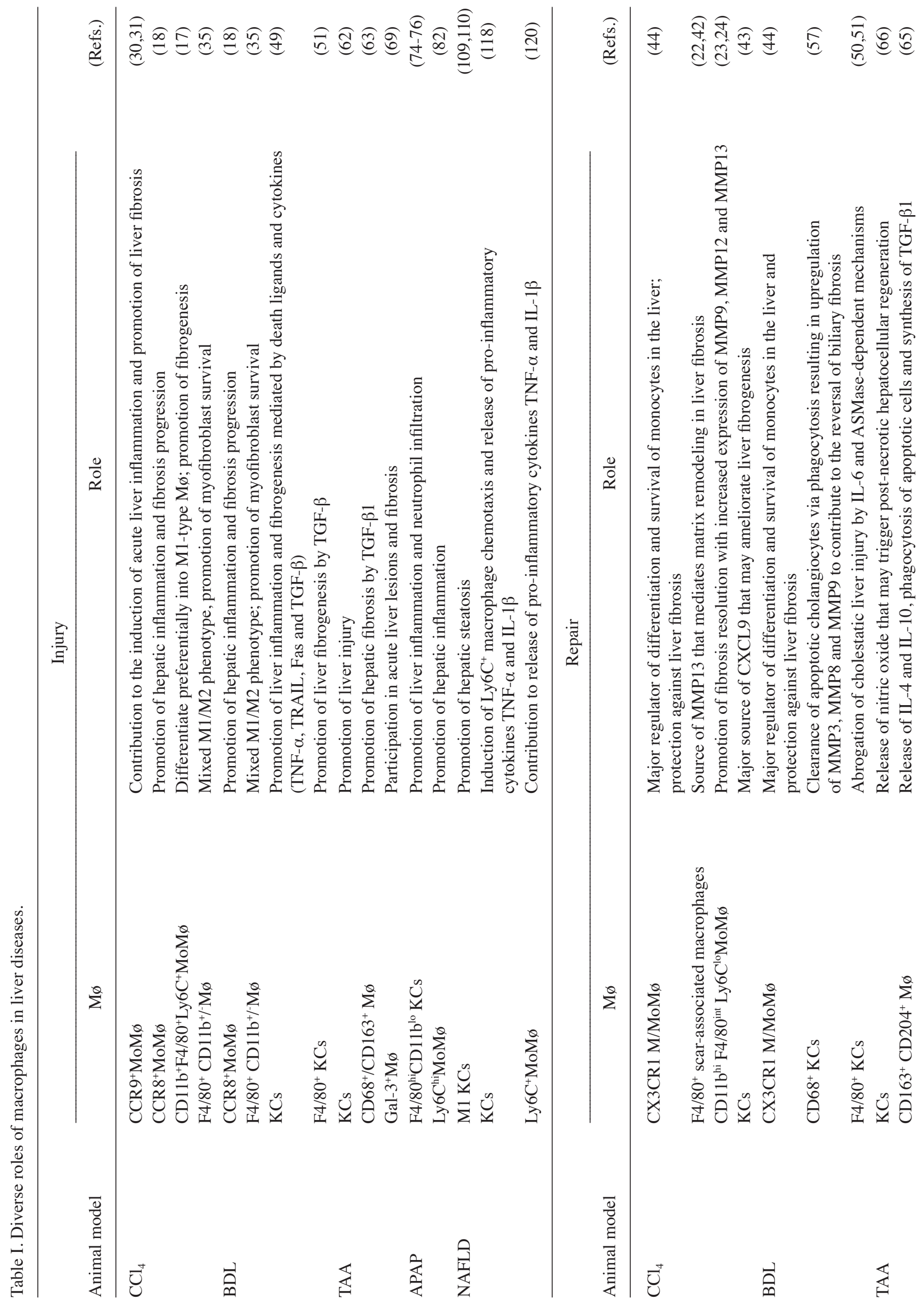




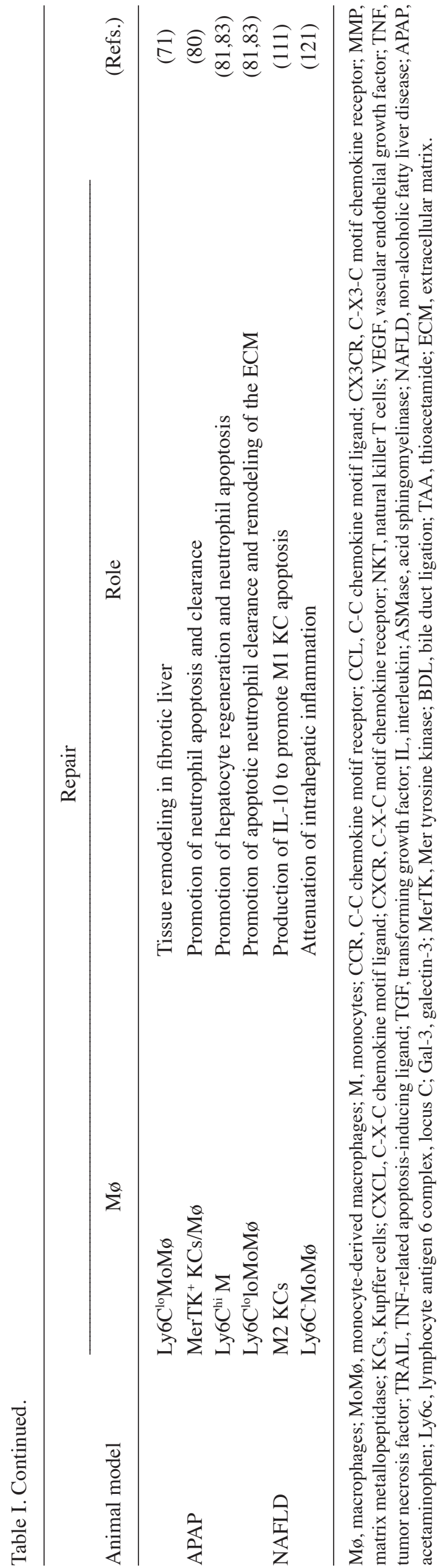

promote the resolution of hepatic damage and fibrosis. Thus, novel methods to improve liver injury or fibrosis focus on targeting liver macrophages. These interventions regulate the activation of KCs (e.g., by inhibiting bacterial translocation or changing the composition of bile acid), inflammatory monocyte migration (e.g., against various chemokines or chemokine receptors), or macrophage polarization and differentiation (e.g., by targeted delivery of nanoparticles) (125). However, different interventions lack scientific comparison and require further evaluation of their effectiveness. Numerous studies only provided an immune function analysis at the organ level and did not specify the phenotypes of liver macrophages. Furthermore, the underlying mechanisms and triggers of hepatic macrophage phenotype switching during different stages of liver injury have not been well studied. Therefore, an in-depth study of the genomes and phenotypes of liver macrophages is required.

\title{
6. Conclusions
}

Liver macrophages, termed KCs and MoMø, regulate liver repair following injury (Table I). They may worsen hepatic damage by producing ROS and other inflammatory mediators that induce leukocyte aggregation and exacerbate hepatic injury. However, they also produce a variety of anti-inflammatory cytokines, including IL-4, IL-10, IL-13 and TGF- $\beta$, that downregulate macrophage function and switch their phenotype to that of restorative macrophages with pro-resolving activity. Consequently, liver macrophages may serve as potential targets for liver disease treatment, and studies focusing on this strategy will become increasingly frequent.

\section{Acknowledgements}

Not applicable.

\section{Funding}

The present study was supported by the National Key Research and Development Program of China (grant no. 2016YFA0101001) and the National Natural Science Foundation of China (grant no. 81471794).

\section{Availability of data and materials}

All data generated or analyzed during this study are included in this published article.

\begin{abstract}
Authors' contributions
XD wrote the manuscript and constructed the figures. JL and YX revised the manuscript. HC designed and revised the manuscript. All authors have read and approved the final manuscript.
\end{abstract}

\section{Ethics approval and consent to participate}

Not applicable.

\section{Patient consent for publication}

Not applicable. 


\section{Competing interests}

The authors declare that they have no competing interests.

\section{References}

1. Wynn TA and Vannella KM: Macrophages in tissue repair, regeneration, and fibrosis. Immunity 44: 450-462, 2016.

2. Vannella KM and Wynn TA: Mechanisms of organ injury and repair by macrophages. Annu Rev Physiol 79: 593-617, 2017.

3. Epelman S, Lavine KJ and Randolph GJ: Origin and functions of tissue macrophages. Immunity 41: 21-35, 2014.

4. Ginhoux F and Guilliams M: Tissue-resident macrophage ontogeny and homeostasis. Immunity 44: 439-449, 2016.

5. Gregory SH and Wing EJ: Neutrophil-Kupffer cell interaction: A critical component of host defenses to systemic bacterial infections. J Leukoc Biol 72: 239-248, 2002.

6. Ganz T: Macrophages and systemic iron homeostasis. J Innate Immun 4: 446-453, 2012.

7. Schulz C, Gomez Perdiguero E, Chorro L, Szabo-Rogers H, Cagnard N, Kierdorf K, Prinz M, Wu B, Jacobsen SE, et al: A lineage of myeloid cells independent of Myb and hematopoietic stem cells. Science 336: 86-90, 2012.

8. Davies LC, Jenkins SJ, Allen JE and Taylor PR: Tissue-resident macrophages. Nat Immunol 14: 986-995, 2013

9. Klein I, Cornejo JC, Polakos NK, John B, Wuensch SA, Topham DJ, Pierce RH and Crispe IN: Kupffer cell heterogeneity: Functional properties of bone marrow derived and sessile hepatic macrophages. Blood 110:4077-4085, 2007.

10. Murray PJ, Allen JE, Biswas SK, Fisher EA, Gilroy DW, Goerdt S, Gordon S, Hamilton JA, Ivashkiv LB, Lawrence T, et al: Macrophage activation and polarization: Nomenclature and experimental guidelines. Immunity 41: 14-20, 2014.

11. Stein M, Keshav S, Harris N and Gordon S: Interleukin 4 potently enhances murine macrophage mannose receptor activity: A marker of alternative immunologic macrophage activation. J Exp Med 176: 287-292, 1992.

12. Laskin DL, Sunil VR, Gardner CR and Laskin JD: Macrophages and tissue injury: Agents of defense or destruction? Annu Rev Pharmacol Toxicol 51: 267-288, 2011.

13. Martinez FO and Gordon S: The M1 and M2 paradigm of macrophage activation: Time for reassessment. F1000Prime Rep 6: 13, 2014.

14. Weber LW, Boll M and Stampfl A: Hepatotoxicity and mechanism of action of haloalkanes: Carbon tetrachloride as a toxicological model. Crit Rev Toxicol 33: 105-136, 2003.

15. Mehendale HM: Tissue repair: An important determinant of final outcome of toxicant-induced injury. Toxicol Pathol 33: 41-51, 2005

16. Tacke F: Functional role of intrahepatic monocyte subsets for the progression of liver inflammation and liver fibrosis in vivo. Fibrogenesis Tissue Repair 5 (Suppl 1): S27, 2012.

17. Karlmark KR, Weiskirchen R, Zimmermann HW, Gassler N, Ginhoux F, Weber C, Merad M, Luedde T, Trautwein C and Tacke F: Hepatic recruitment of the inflammatory $\mathrm{Grl}^{+}$monocyte subset upon liver injury promotes hepatic fibrosis. Hepatology 50: 261-274, 2009

18. Heymann F, Hammerich L, Storch D, Bartneck M, Huss S, Russeler V, Gassler N, Lira SA, Luedde T, Trautwein C, et al: Hepatic macrophage migration and differentiation critical for liver fibrosis is mediated by the chemokine receptor $\mathrm{C}-\mathrm{C}$ motif chemokine receptor 8 in mice. Hepatology 55: 898-909, 2012.

19. Geissmann F, Manz MG, Jung S, Sieweke MH, Merad M and Ley K: Development of monocytes, macrophages, and dendritic cells. Science 327: 656-661, 2010.

20. Carlin LM, Stamatiades EG, Auffray C, Hanna RN, Glover L, Vizcay-Barrena G, Hedrick CC, Cook HT, Diebold S and Geissmann F: Nr4a1-dependent Ly6C(low) monocytes monitor endothelial cells and orchestrate their disposal. Cell 153: 362-375, 2013.

21. Mildner A, Schonheit J, Giladi A, David E, Lara-Astiaso D, Lorenzo-Vivas E, Paul F, Chappell-Maor L, Priller J, Leutz A, et al: Genomic characterization of murine monocytes reveals C/EBP $\beta$ transcription factor dependence of Ly6C-Cells. Immunity 46: 849-862 e847, 2017.

22. Duffield JS, Forbes SJ, Constandinou CM, Clay S, Partolina M, Vuthoori S, Wu S, Lang R and Iredale JP: Selective depletion of macrophages reveals distinct, opposing roles during liver injury and repair. J Clin Invest 115: 56-65, 2005.
23. Ramachandran P, Pellicoro A, Vernon MA, Boulter L, Aucott RL, Ali A, Hartland SN, Snowdon VK, Cappon A, Gordon-Walker TT, et al: Differential Ly-6C expression identifies the recruited macrophage phenotype, which orchestrates the regression of murine liver fibrosis. Proc Natl Acad Sci USA 109: E3186-3195, 2012.

24. Ma PF, Gao CC, Yi J, Zhao JL, Liang SQ, Zhao Y, Ye YC, Bai J, Zheng QJ, Dou KF, et al: Cytotherapy with M1-polarized macrophages ameliorates liver fibrosis by modulating immune microenvironment in mice. J Hepatol 67: 770-779, 2017.

25. Ramachandran P, Iredale JP and Fallowfield JA: Resolution of liver fibrosis: Basic mechanisms and clinical relevance. Semin Liver Dis 35: 119-131, 2015.

26. Tacke F and Zimmermann HW: Macrophage heterogeneity in liver injury and fibrosis. J Hepatol 60: 1090-1096, 2014.

27. Wree A and Marra F: The inflammasome in liver disease. J Hepatol 65: 1055-1056, 2016.

28. Weber LWD, Boll M and Stampfl A: Hepatotoxicity and mechanism of action of haloalkanes: Carbon tetrachloride as a toxicological model. Crit Rev Toxicol 33: 105-136, 2003.

29. Marra F and Tacke F: Roles for chemokines in liver disease. Gastroenterology 147: 577-594.e571, 2014.

30. Nakamoto N, Ebinuma H, Kanai T, Chu PS, Ono Y, Mikami Y, Ojiro K, Lipp M, Love PE, Saito H, et al: CCR9 ${ }^{+}$macrophages are required for acute liver inflammation in mouse models of hepatitis. Gastroenterology 142: 366-376, 2012.

31. Chu PS, Nakamoto N, Ebinuma H, Usui S, Saeki K, Matsumoto A, Mikami Y, Sugiyam K, Tomita K, Kanai T, et al: C-C motif chemokine receptor 9 positive macrophages activate hepatic stellate cells and promote liver fibrosis in mice. Hepatology 58: 337-350, 2013.

32. Hamidzadeh K, Christensen SM, Dalby E, Chandrasekaran P and Mosser DM: Macrophages and the Recovery from Acute and Chronic Inflammation. Annu Rev Physiol 79: 567-592, 2017.

33. Zimmers TA, McKillop IH, Pierce RH, Yoo JY and Koniaris LG: Massive liver growth in mice induced by systemic interleukin 6 administration. Hepatology 38: 326-334, 2003.

34. Li Y, Schwabe RF, DeVries-Seimon T, Yao PM, Gerbod-Giannone MC, Tall AR, Davis RJ, Flavell R, Brenner DA and Tabas I: Free cholesterol-loaded macrophages are an abundant source of tumor necrosis factor-alpha and interleukin-6: Model of NF-kappaB- and map kinase-dependent inflammation in advanced atherosclerosis. J Biol Chem 280: 21763-21772, 2005.

35. Pradere JP, Kluwe J, De Minicis S, Jiao JJ, Gwak GY, Dapito DH, Jang MK, Guenther ND, Mederacke I, Friedman R, et al: Hepatic macrophages but not dendritic cells contribute to liver fibrosis by promoting the survival of activated hepatic stellate cells in mice. Hepatology 58: 1461-1473, 2013.

36. Lotersztajn S, Julien B, Teixeira-Clerc F, Grenard P and Mallat A: Hepatic fibrosis: Molecular mechanisms and drug targets. Annu Rev Pharmacol Toxicol 45: 605-628, 2005.

37. Borkham-Kamphorst E, Kovalenko E, van Roeyen CR, Gassler N, Bomble M, Ostendorf T, Floege J, Gressner AM and Weiskirchen R: Platelet-derived growth factor isoform expression in carbon tetrachloride-induced chronic liver injury. Lab Invest 88: 1090-1100, 2008.

38. Hao ZM, Fan XB, Li S, Lv YF, Su HQ, Jiang HP and Li HH: Vaccination with Platelet-Derived Growth Factor B Kinoids Inhibits CCl4-Induced Hepatic Fibrosis in Mice. J Pharmacol Exp Ther 342: 835-842, 2012.

39. Perugorria MJ, Murphy LB, Fullard N, Chakraborty JB, Vyrla D, Wilson CL, Oakley F, Mann J and Mann DA: Tumor progression locus $2 /$ Cot is required for activation of extracellular regulated kinase in liver injury and toll-like receptor-induced TIMP-1 gene transcription in hepatic stellate cells in mice. Hepatology 57: 1238-1249, 2013.

40. Louis H, Van Laethem JL, Wu W, Quertinmont E, Degraef C, Van den Berg K, Demols A, Goldman M, Le Moine O, Geerts A and Devière J: Interleukin-10 controls neutrophilic infiltration, hepatocyte proliferation, and liver fibrosis induced by carbon tetrachloride in mice. Hepatology 28: 1607-1615, 1998.

41. Thompson K, Maltby J, Fallowfield J, McAulay M, Millward-Sadler $\mathrm{H}$ and Sheron N: Interleukin-10 expression and function in experimental murine liver inflammation and fibrosis. Hepatology 28: 1597-1606, 1998.

42. Fallowfield JA, Mizuno M, Kendall TJ, Constandinou CM, Benyon RC, Duffield JS and Iredale JP: Scar-associated macrophages are a major source of hepatic matrix metalloproteinase-13 and facilitate the resolution of murine hepatic fibrosis. J Immunol 178: 5288-5295, 2007. 
43. Wasmuth HE, Lammert F, Zaldivar MM, Weiskirchen R, Hellerbrand C, Scholten D, Berres ML, Zimmermann H, Streetz KL, Tacke F, et al: Antifibrotic effects of CXCL9 and its receptor CXCR3 in livers of mice and humans. Gastroenterology 137: 309-319, 319 e301-303, 2009.

44. Karlmark KR, Zimmermann HW, Roderburg C, Gassler N, Wasmuth HE, Luedde T, Trautwein $C$ and Tacke F: The fractalkine receptor $\mathrm{CX}(3) \mathrm{CR} 1$ protects against liver fibrosis by controlling differentiation and survival of infiltrating hepatic monocytes. Hepatology 52: 1769-1782, 2010.

45. Scott-Conner CE and Grogan JB: The pathophysiology of biliary obstruction and its effect on phagocytic and immune function. J Surg Res 57: 316-336, 1994.

46. Lazar G, Paszt A, Kaszaki J, Duda E, Szakacs J, Tiszlavicz L, Boros M, Balogh A and Lazar G: Kupffer cell phagocytosis blockade decreases morbidity in endotoxemic rats with obstructive jaundice. Inflamm Res 51: 511-518, 2002.

47. Faubion WA, Guicciardi ME, Miyoshi H, Bronk SF, Roberts PJ, Svingen PA, Kaufmann SH and Gores GJ: Toxic bile salts induce rodent hepatocyte apoptosis via direct activation of Fas. J Clin Invest 103: 137-145, 1999.

48. Canbay A, Higuchi H, Bronk SF, Taniai M, Sebo TJ and Gores GJ: Fas enhances fibrogenesis in the bile duct ligated mouse: A link between apoptosis and fibrosis. Gastroenterology 123: 1323-1330, 2002.

49. Canbay A, Feldstein AE, Higuchi H, Werneburg N, Grambihler A, Bronk SF and Gores GJ: Kupffer cell engulfment of apoptotic bodies stimulates death ligand and cytokine expression. Hepatology 38: 1188-1198, 2003.

50. Gehring S, Dickson EM, San Martin ME, van Rooijen N, Papa EF, Harty MW, Tracy TF Jr. and Gregory SH: Kupffer cells abrogate cholestatic liver injury in mice. Gastroenterology 130 810-822, 2006.

51. Osawa Y, Seki E, Adachi M, Suetsugu A, Ito H, Moriwaki H, Seishima M and Nagaki M: Role of acid sphingomyelinase of kupffer cells in cholestatic liver injury in mice. Hepatology 51: 237-245, 2010.

52. Seki E, De Minicis S, Osterreicher CH, Kluwe J, Osawa Y, Brenner DA and Schwabe RF: TLR4 enhances TGF-beta signaling and hepatic fibrosis. Nat Med 13: 1324-1332, 2007.

53. Meng F, Wang K, Aoyama T, Grivennikov SI, Paik Y, Scholten D, Cong M, Iwaisako K, Liu X, Zhang M, et al: Interleukin-17 Signaling in inflammatory, kupffer cells, and hepatic stellate cells exacerbates liver fibrosis in mice. Gastroenterology 143 : 765-776.e3, 2012.

54. Steinman L: A brief history of $\mathrm{T}(\mathrm{H}) 17$, the first major revision in the $\mathrm{T}(\mathrm{H}) 1 / \mathrm{T}(\mathrm{H}) 2$ hypothesis of $\mathrm{T}$ cell-mediated tissue damage. Nat Med 13: 139-145, 2007.

55. Ying HZ, Chen Q, Zhang WY, Zhang HH, Ma Y, Zhang SZ, Fang $\mathrm{J}$ and $\mathrm{Yu} \mathrm{CH}$ : PDGF signaling pathway in hepatic fibrosis pathogenesis and therapeutics. Mol Med Report 16: 7879-7889, 2017.

56. Guillot A, Hamdaoui N, Bizy A, Zoltani K, Souktani R, Zafrani ES, Mallat A, Lotersztajn S and Lafdil F: Cannabinoid receptor 2 counteracts interleukin-17-induced immune and fibrogenic responses in mouse liver. Hepatology 59: 296-306, 2014.

57. Popov Y, Sverdlov DY, Bhaskar KR, Sharma AK, Millonig G, Patsenker E, Krahenbuhl S, Krahenbuhl L and Schuppan D: Macrophage-mediated phagocytosis of apoptotic cholangiocytes contributes to reversal of experimental biliary fibrosis. Am J Physiol Gastrointest Liver Physiol 298: G323-G334, 2010.

58. Chilakapati J, Shankar K, Korrapati MC, Hill RA and Mehendale HM: Saturation toxicokinetics of thioacetamide: Role in initiation of liver injury. Drug Metab Dispos 33: 1877-1885, 2005 .

59. Kuramochi M, Izawa T, Pervin M, Bondoc A, Kuwamura M and Yamate $\mathrm{J}$ : The kinetics of damage-associated molecular patterns (DAMPs) and toll-like receptors during thioacetamide-induced acute liver injury in rats. Exp Toxicol Pathol 68: 471-477, 2016.

60. Erridge C: Endogenous ligands of TLR2 and TLR4: Agonists or assistants? J Leukoc Biol 87: 989-999, 2010.

61. Fujisawa K, Miyoshi T, Tonomura Y, Izawa T, Kuwamura M, Torii M and Yamate J: Relationship of heat shock protein 25 with reactive macrophages in thioacetamide-induced rat liver injury. Exp Toxicol Pathol 63: 599-605, 2011

62. Andres D, Sanchez-Reus I, Bautista M and Cascales M: Depletion of Kupffer cell function by gadolinium chloride attenuates thioacetamide-induced hepatotoxicity-Expression of metallothionein and HSP70. Biochem Pharmacol 66: 917-926, 2003.
63. Ide M,Kuwamura M,Kotani T, Sawamoto O and Yamate J: Effects of gadolinium chloride $(\mathrm{GdCl} 3)$ on the appearance of macrophage populations and fibrogenesis in thioacetamide-induced rat hepatic lesions. J Comp Pathol 133: 92-102, 2005.

64. Ide M, Yamate J, Machida Y, Nakanishi M, Kuwamura M, Kotani $\mathrm{T}$ and Sawamoto O: Emergence of different macrophage populations in hepatic fibrosis following thioacetamide-induced acute hepatocyte injury in rats. J Comp Pathol 128: 41-51, 2003.

65. GolbarHM,Izawa T, Wijesundera KK, Bondoc A, Tennakoon AH, Kuwamura M and Yamate J: Depletion of hepatic macrophages aggravates liver lesions induced in rats by thioacetamide (TAA). Toxicol Pathol 44: 246-258, 2016.

66. DiezFernandez C, Sanz N, Bosca L, Hortelano S and Cascales M: Involvement of nitric oxide synthesis in hepatic perturbations induced in rats by a necrogenic dose of thioacetamide. Br J Pharmacol 121: 820-826, 1997.

67. Hernandez-Gea V, Ghiassi-Nejad Z, Rozenfeld R, Gordon R, Fiel MI, Yue ZY, Czaja MJ and Friedman SL: Autophagy releases lipid that promotes fibrogenesis by activated hepatic stellate cells in mice and in human tissues. Gastroenterology 142: 938-946, 2012.

68. Palacios RS, Roderfeld M, Hemmann S, Rath T, Atanasova S, Tschuschner A, Gressner OA, Weiskirchen R, Graf J and Roeb E: Activation of hepatic stellate cells is associated with cytokine expression in thioacetamide-induced hepatic fibrosis in mice. Lab Invest 88: 1192-1203, 2008.

69. Traber PG, Chou H, Zomer E, Hong F, Klyosov A, Fiel MI and Friedman SL: Regression of fibrosis and reversal of cirrhosis in rats by galectin inhibitors in thioacetamide-induced liver disease. PLoS One 8: e75361, 2013.

70. Wijesundera KK, Izawa $\mathrm{T}$, Tennakoon AH, Murakami $\mathrm{H}$, Golbar HM, Katou-Ichikawa C, Tanaka M, Kuwamura M and Yamate J: M1- and M2-macrophage polarization in rat liver cirrhosis induced by thioacetamide (TAA), focusing on Iba1 and galectin-3. Exp Mol Pathol 96: 382-392, 2014.

71. Yada A, Iimuro Y, Uyama N, Uda Y, Okada T and Fujimoto J: Splenectomy attenuates murine liver fibrosis with hypersplenism stimulating hepatic accumulation of Ly-6C(lo) macrophages. J Hepatol 63: 905-916, 2015.

72. Jaeschke H and Bajt ML: Intracellular signaling mechanisms of acetaminophen-induced liver cell death. Toxicol Sci 89: 31-41, 2006.

73. Krenkel O, Mossanen Jana C and Tacke F: Immune mechanisms in acetaminophen-induced acute liver failure. Hepatobiliary Surgery and Nutrition 3: 331-343, 2014.

74. Yang H, Hreggvidsdottir HS, Palmblad K, Wang H, Ochani M, Li J, Lu B, Chavan S, Rosas-Ballina M, Al-Abed Y, et al: A critical cysteine is required for HMGB1 binding to Toll-like receptor 4 and activation of macrophage cytokine release. Proc Natl Acad Sci USA 107: 11942-11947, 2010.

75. Wang X, Sun R, Wei H and Tian Z: High-mobility group box 1 (HMGB1)-toll-like receptor (TLR)4-interleukin (IL)-23-IL-17A axis in drug-induced damage-associated lethal hepatitis: Interaction of $\gamma \delta \mathrm{T}$ cells with macrophages. Hepatology 57: 373-384, 2013.

76. Marques PE, Amaral SS, Pires DA, Nogueira LL, Soriani FM, Lima BH, Lopes GA, Russo RC, Avila TV, Melgaco JG, et al: Chemokines and mitochondrial products activate neutrophils to amplify organ injury during mouse acute liver failure. Hepatology 56: 1971-1982, 2012.

77. Marques PE, Amaral SS, Pires DA, Nogueira LL, Soriani FM, Lima BH, Lopes GA, Russo RC, Avila TV, Melgaco JG, et al: Chemokines and mitochondrial products activate neutrophils to amplify organ injury during mouse acute liver failure. Hepatology 56: 1971-1982, 2012.

78. Williams CD, Bajt ML, Sharpe MR, McGill MR, Farhood A and Jaeschke H: Neutrophil activation during acetaminophen hepatotoxicity and repair in mice and humans. Toxicol Appl Pharmacol 275: 122-133, 2014.

79. Jaeschke H, Williams CD, Ramachandran A and Bajt ML: Acetaminophen hepatotoxicity and repair: The role of sterile inflammation and innate immunity. Liver Int 32: 8-20, 2012.

80. Triantafyllou E, Pop OT, Possamai LA, Wilhelm A, Liaskou E, Singanayagam A, Bernsmeier C, Khamri W, Petts G, Dargue R, et al: MerTK expressing hepatic macrophages promote the resolution of inflammation in acute liver failure. Gut 67: 333-347, 2018. 
81.Zigmond E, Samia-Grinberg S, Pasmanik-Chor M, Brazowski E, Shibolet O, Halpern Z and Varol C: Infiltrating monocyte-derived macrophages and resident kupffer cells display different ontogeny and functions in acute liver injury. J Immunol 193: 344-353, 2014.

82. Mossanen JC, Krenkel O, Ergen C, Govaere O, Liepelt A, Puengel T, Heymann F, Kalthoff S, Lefebvre E, Eulberg D, et al: Chemokine (C-C motif) receptor 2-positive monocytes aggravate the early phase of acetaminophen-induced acute liver injury. Hepatology 64: 1667-1682, 2016.

83. Graubardt N, Vugman M, Mouhadeb O, Caliari G, Pasmanik-Chor M, Reuveni D, Zigmond E, Brazowski E, David E, Chappell-Maor L, et al: Ly6C(hi) monocytes and their macrophage descendants regulate neutrophil function and clearance in acetaminophen-induced liver injury. Front Immunol 8: 626, 2017.

84. Stachlewitz RF, Seabra V, Bradford B, Bradham CA, Rusyn I, Germolec D and Thurman RG: Glycine and uridine prevent D-galactosamine hepatotoxicity in the rat: Role of Kupffer cells Hepatology 29: 737-745, 1999

85. Xiong QB, Hase K, Tezuka Y, Namba T and Kadota S Acteoside inhibits apoptosis in D-galactosamine and lipopolysaccharide-induced liver injury. Life Sci 65: 421-430, 1999.

86. Galanos C, Freudenberg MA and Reutter W: Galactosamine-induced sensitization to the lethal effects of endotoxin. Proc Natl Acad Sci USA 76: 5939-5943, 1979.

87. Kitazawa T, Tsujimoto T, Kawaratani H, Fujimoto $M$ and Fukui H: Expression of Toll-like receptor 4 in various organs in rats with D-galactosamine-induced acute hepatic failure. J Gastroenterol Hepatol 23: E494-E498, 2008.

88. Ben Ari Z, Avlas O, Pappo O, Zilbermints V, Cheporko Y, Bachmetov L, Zemel R, Shainberg A, Sharon E, Grief F, et al: Reduced hepatic injury in toll-like receptor 4-deficient mice following D-galactosamine/lipopolysaccharide-induced fulminant hepatic failure. Cell Physiol Biochem 29: 41-50, 2012.

89. Ilyas G, Zhao EP, Liu K, Lin Y, Tesfa L, Tanaka KE and Czaja MJ: Macrophage autophagy limits acute toxic liver injury in mice through down regulation of interleukin-1 $\beta$. J Hepatol 64 $118-127,2016$

90.Li L, Duan CL, Zhao Y, Zhang XF, Yin HY, Wang TX, Huang CX, Liu SH, Yang SY and Li XJ: Preventive effects of interleukin-6 in lipopolysaccharide/D-galactosamine induced acute liver injury via regulating inflammatory response in hepatic macrophages. Int Immunopharmacol 51: 99-106, 2017.

91. Dejager L and Libert C: Tumor necrosis factor alpha mediates the lethal hepatotoxic effects of poly(I:C) in D-galactosamine-sensitized mice. Cytokine 42: 55-61, 2008.

92. Wolf AM, Wolf D, Rumpold H, Ludwiczek S, Enrich B Gastl G, Weiss G and Tilg H: The kinase inhibitor imatinib mesylate inhibits TNF-alpha production in vitro and prevents TNF-dependent acute hepatic inflammation. Proc Natl Acad Sci USA 102: 13622-13627, 2005

93. Jiang W, Sun R, Wei HM and Tian ZG: Toll-like receptor 3 ligand attenuates LPS-induced liver injury by down-regulation of toll-like receptor 4 expression on macrophages. Proc Natl Acad Sci USA 102: 17077-17082, 2005.

94.Zheng XF, Hu XY, Ma B, Fang H, Zhang F, Mao YF, Yang FY, Xiao SC and Xia ZF: Interleukin-35 attenuates D-galactosamine/lipopolysaccharide-induced liver injury via enhancing interleukin-10 production in kupffer cells. Front Pharmacol 9: 959, 2018.

95. Lu L, Zhou HM, Ni M, Wang XH, Busuttil R, Kupiec-Weglinski J and Zhai Y: Innate immune regulations and liver ischemia-reperfusion injury. Transplantation 100: 2601-2610, 2016

96. Tsung A, Sahai R, Tanaka H, Nakao A, Fink MP, Lotze MT, Yang H, Li J, Tracey KJ, Geller DA, et al: The nuclear factor HMGB1 mediates hepatic injury after murine liver ischemia-reperfusion. J Exp Med 201: 1135-1143, 2005

97. Mosher B, Dean R, Harkema J, Remick D, Palma J and Crockett E: Inhibition of Kupffer cells reduced CXC chemokine production and liver injury. J Surg Res 99: 201-210, 2001.

98. Jiang W, Tang W, Geng Q and Xu X: Inhibition of toll-like receptor 4 with vasoactive intestinal peptide attenuates liver ischemia-reperfusion injury. Transplant Proc 43: 1462-1467, 2011.

99. Devey L, Ferenbach D, Mohr E, Sangster K, Bellamy CO, Hughes $\mathrm{J}$ and Wigmore SJ: Tissue-resident macrophages protect the liver from ischemia reperfusion injury via a heme oxygenase-1-dependent mechanism. Mol Ther 17: 65-72, 2009.
100. Ellett JD, Atkinson C, Evans ZP, AmaniZ, Balish E, Schmidt MG, van Rooijen N, Schnellmann RG and Chavin KD: Murine Kupffer cells are protective in total hepatic ischemia/reperfusion injury with bowel congestion through IL-10. J Immunol 184: 5849-5858, 2010.

101. Ke B, Shen XD, Gao F, Ji HF, Qiao B, Zhai Y, Farmer DG, Busuttil RW and Kupiec-Weglinski JW: Adoptive transfer of Ex Vivo HO-1 modified bone marrow-derived macrophages prevents liver ischemia and reperfusion injury. Mol Ther 18 1019-1025, 2010.

102. Ke B, Shen XD, Ji H, Kamo N, Gao F, Freitas MC, Busuttil RW and Kupiec-Weglinski JW: HO-1-STAT3 axis in mouse liver ischemia/reperfusion injury: Regulation of TLR4 innate responses through PI3K/PTEN signaling. J Hepatol 56: 359-366, 2012.

103. Ji H, Shen X, Gao F, Ke B, Freitas MC, Uchida Y, Busuttil RW, Zhai Y and Kupiec-Weglinski JW: Programmed death-1/B7-H1 negative costimulation protects mouse liver against ischemia and reperfusion injury. Hepatology 52: 1380-1389, 2010.

104. Devisscher L, Verhelst X, Colle I, Van Vlierberghe H and Geerts A: The role of macrophages in obesity-driven chronic liver disease. J Leukoc Biol 99: 693-698, 2016.

105. Lumeng Carey N, Bodzin Jennifer L and Saltiel Alan R: Obesity induces a phenotypic switch in adipose tissue macrophage polarization. J Clin Invest 117: 175-184, 2007.

106. Neuschwander-Tetri Brent A: Hepatic lipotoxicity and the pathogenesis of nonalcoholic steatohepatitis: The central role of nontriglyceride fatty acid metabolites. Hepatology 52: 774-788, 2010.

107. Ying W, Riopel M, Bandyopadhyay G, Dong Y, Birmingham A, Seo JB, Ofrecio JM, Wollam J, Hernandez-Carretero A, $\mathrm{Fu}$ W, et al: Adipose tissue macrophage-derived exosomal miRNAs can modulate in vivo and in vitro insulin sensitivity. Cell 171: 372-384 e312, 2017.

108. Luo W, Xu Q, Wang Q, Wu H and Hua J: Effect of modulation of PPAR- $\gamma$ activity on Kupffer cells M1/M2 polarization in the development of non-alcoholic fatty liver disease. Sci Rep 7: 44612, 2017.

109. Stienstra R, Saudale F, Duval C, Keshtkar S, Groener JE, van Rooijen N, Staels B, Kersten S and Mueller M: Kupffer cells promote hepatic steatosis via interleukin-1 beta-dependent suppression of peroxisome proliferator-activated receptor alpha activity. Hepatology 51: 511-522, 2010.

110. Huang W, Metlakunta A, Dedousis N, Zhang P, Sipula I, Dube John J, Scott Donald K and O'Doherty Robert M: Depletion of liver kupffer cells prevents the development of diet-induced hepatic steatosis and insulin resistance. Diabetes 59: 347-357, 2010

111. Wan J, Benkdane M, Teixeira-Clerc F, Bonnafous S, Louvet A, Lafdil F, Pecker F, Tran A, Gual P, Mallat A, et al: M2 kupffer cells promote M1 kupffer cell apoptosis: A protective mechanism against alcoholic and nonalcoholic fatty liver disease. Hepatology 59: 130-142, 2014.

112. Day CP and James OF: Steatohepatitis: A tale of two 'hits'? Gastroenterology 114: 842-845, 1998.

113. Tilg $\mathrm{H}$ and Moschen AR: Evolution of inflammation in nonalcoholic fatty liver disease: The multiple parallel hits hypothesis. Hepatology 52: 1836-1846, 2010.

114. Malhi H and Gores GJ: Molecular mechanisms of lipotoxicity in nonalcoholic fatty liver disease. Semin Liver Dis 28: 360-369, 2008.

115. Ibrahim SH, Hirsova P, Tomita K, Bronk SF, Werneburg NW, Harrison SA, Goodfellow VS, Malhi H and Gores GJ: Mixed lineage kinase 3 mediates release of $\mathrm{C}-\mathrm{X}-\mathrm{C}$ motif ligand 10-bearing chemotactic extracellular vesicles from lipotoxic hepatocytes. Hepatology 63: 731-744, 2016.

116. Idrissova L, Malhi H, Werneburg NW, LeBrasseur NK, Bronk SF, Fingas C, Tchkonia T, Pirtskhalava T, White TA, Stout MB, et al: TRAIL receptor deletion in mice suppresses the inflammation of nutrient excess. J Hepatol 62: 1156-1163, 2015.

117. Li L, Chen L, Hu L, Liu Y, Sun HY, Tang J, Hou YJ, Chang YX, Tu QQ, Feng GS, et al: Nuclear factor high-mobility group box 1 mediating the activation of toll-like receptor 4 signaling in hepatocytes in the early stage of nonalcoholic fatty liver disease in mice. Hepatology 54: 1620-1630, 2011

118. Reid DT, Reyes JL, McDonald BA, Vo T, Reimer RA and Eksteen B: Kupffer cells undergo fundamental changes during the development of experimental NASH and are critical in initiating liver damage and inflammation. PLoS One 11: e0159524, 2016. 
119. Baeck C, Wehr A, Karlmark Karlin R, Heymann F, Vucur M, Gassler N, Huss S, Klussmann S, Eulberg D, Luedde T, et al: Pharmacological inhibition of the chemokine CCL2 (MCP-1) diminishes liver macrophage infiltration and steatohepatitis in chronic hepatic injury. Gut 61: 416-426, 2012.

120. Miura K, Yang L, van Rooijen N, Ohnishi H and Seki E: Hepatic recruitment of macrophages promotes nonalcoholic steatohepatitis through CCR2. Am J Physiol-Gastroint Liver Physiol 302: G1310-G1321, 2012.

121. McMahan RH, Wang XXX, Cheng LL, Krisko T, Smith M, El Kasmi K, Pruzanski M, Adorini L, Golden-Mason L, Levi M, et al: Bile acid receptor activation modulates hepatic monocyte activity and improves nonalcoholic fatty liver disease. J Biol Chem 288: 11761-11770, 2013.
122. Miura K, Kodama Y, Inokuchi S, Schnabl B, Aoyama T, Ohnishi H, Olefsky JM, Brenner DA and Seki E: Toll-like receptor 9 promotes steatohepatitis by induction of interleukin-1 beta in mice. Gastroenterology 139: 323-334.e7, 2010.

123. Tomita K, Tamiya G, Ando S, Ohsumi K, Chiyo T, Mizutani A, Kitamura N, Toda K, Kaneko T, Horie Y, et al: Tumour necrosis factor alpha signalling through activation of Kupffer cells plays an essential role in liver fibrosis of non-alcoholic steatohepatitis in mice. Gut 55: 415-424, 2006

124. Wang J, Leclercq I, Brymora JM, Xu N, Ramezani-Moghadam M, London RM, Brigstock D and George J: Kupffer cells mediate leptin-induced liver fibrosis. Gastroenterology 137: 713-723, 2009.

125. Tacke F: Targeting hepatic macrophages to treat liver diseases. J Hepatol 66: 1300-1312, 2017. 